\title{
Chronic alcohol abuse affects the clinical course and outcome of community-acquired bacterial meningitis
}

\author{
Marcin Paciorek ${ }^{1}$ (D) Agnieszka Bednarska ${ }^{1} \cdot$ Dominika Krogulec $^{1} \cdot$ Michał Makowiecki $^{1} \cdot$ Justyna D Kowalska $^{1}$. \\ Dominik Bursa ${ }^{1}$ - Anna Świderska ${ }^{2}$ - Joanna Puła ${ }^{1}$ - Joanna Raczyńska ${ }^{1}$. Agata Skrzat-Klapaczyńska ${ }^{1}$. \\ Magdalena Zielenkiewicz ${ }^{3}$. Marek Radkowski ${ }^{4} \cdot$ Tomasz Laskus $^{1}$ • Andrzej Horban ${ }^{1}$
}

Received: 16 May 2019 / Accepted: 23 July 2019 / Published online: 7 August 2019

(C) The Author(s) 2019

\begin{abstract}
The aim of the study was to determine the effect of chronic alcohol abuse on the course and outcome of bacterial meningitis (BM). We analyzed records of patients with BM who were hospitalized between January 2010 and December 2017 in the largest neuroinfection center in Poland. Out of 340 analyzed patients, 45 (13.2\%) were alcoholics. Compared with non-alcoholics, alcoholics were more likely to present with seizures $(p<0.001)$, scored higher on the Sequential Organ Failure Assessment (SOFA) $(p=0.002)$ and lower on the Glasgow Coma Scale (GCS) $(p<0.001)$, and had worse outcome as measured by the Glasgow Outcome Score (GOS) $(p<0.001)$. Furthermore, alcoholics were less likely to complain of headache $(p<0.001)$ and nausea/vomiting $(p=0.005)$ and had lower concentration of glucose in cerebrospinal fluid (CSF) $(p=0.025)$. In the multiple logistic regression analysis, alcoholism was associated with lower GCS $(p=0.036)$, presence of seizures $(p=0.041)$, male gender $(p=0.042)$, and absence of nausea/vomiting $(p=0.040)$. Furthermore, alcoholism $(p=0.031)$, lower GCS score $(p=0.001)$, and higher blood urea concentration $(p=0.018)$ were independently associated with worse outcome measured by GOS. Compared with non-alcoholics, chronic alcohol abusers are more likely to present with seizures, altered mental status, and higher SOFA score and have an increased risk of unfavorable outcome. In multivariate analysis, seizures and low GCS were independently associated with alcoholism, while alcoholism was independently associated with worse outcome.
\end{abstract}

Keywords Bacterial meningitis $\cdot$ Alcoholism $\cdot$ Outcome $\cdot$ SOFA

\section{Introduction}

In Poland, where the registration of bacterial meningitis (BM) cases is mandatory, the annual incidence of BM in the years

Electronic supplementary material The online version of this article (https://doi.org/10.1007/s10096-019-03661-5) contains supplementary material, which is available to authorized users.

Marcin Paciorek

mpaciorek@op.pl

1 Department of Adult Infectious Diseases, Medical University of Warsaw, Warsaw, Poland

2 Medical University of Warsaw, Warsaw, Poland

3 Institute of Mathematics, University of Warsaw, Warsaw, Poland

4 Department of Immunopathology of Infectious and Parasitic Diseases, Medical University of Warsaw, Warsaw, Poland
2010-2017 ranged between 1.97/100,000 and 2.5/100,000 [1-3] which is higher than is some other European countries such as Finland $(0.7 / 100,000)$, Netherlands $(0.94 / 100,000)$, or England and Wales $(1.44 / 100,000)$ [4-6]. Alcohol per capita consumption (in liters of pure alcohol) for population $\geq$ 15 years old was 11.4 in 2010 and 11.6 in 2016 which is similar to many other European countries [7]. Alcoholics are more susceptible to bacterial infections and these infections carry a worse prognosis. There is evidence that the relative risk of bacterial pneumonia correlates with the level of alcohol intake [8]. While this may be in part a consequence of lifestyle and malnutrition, there is evidence that chronic alcohol abuse itself may impair various host immune responses $[9,10]$. The aim of our study was to determine whether chronic alcohol abuse has any impact on clinical manifestations, etiologic factors, and outcome in BM. Such an analysis is rare in the literature and was confined so far to two studies from Netherlands $[11,12]$. 


\section{Materials and methods}

We evaluated records of adult ( $\geq 18$ years old) patients with community-acquired BM who were admitted to the Hospital for Infectious Diseases in Warsaw from January 1, 2010, to December 31, 2017. The diagnosis of BM was based on fulfilling at least one of the following criteria: positive cerebrospinal fluid (CSF) culture, positive CSF Gram staining, and typical CSF findings (pleocytosis $\geq 100$ cells $/ \mu \mathrm{L}$ with $\geq 90 \%$ neutrophils and decrease of CSF glucose level $<2.2 \mathrm{mmol} / \mathrm{L}$ ). Patients with CSF findings typical for BM but negative blood and CSF culture and negative microscopic CSF examination were considered to have BM of unknown etiology. Diagnosis of tuberculous meningitis was based on at least one of the following: positive culture, positive nucleic acid amplification, and positive Ehrlich-Ziehl-Neelsen staining of CSF. Glasgow Coma Scale (GCS) and Sequential Organ Failure Assessment (SOFA) scores were calculated at admission, while Glasgow Outcome Score (GOS) was assessed at the time of discharge from hospital.

Initial antimicrobial treatment followed current guidelines [13]. Patients with meningitis secondary to head trauma, neurosurgical procedures, and hospital-acquired infections were excluded from analysis.

Alcoholism was diagnosed according to the World Health Organization (WHO) criteria [14]. Questions about potential
Table 1 Demographic, clinical, and etiological data in alcoholic and non-alcoholic patients with bacterial meningitis

\begin{tabular}{|c|c|c|c|}
\hline & $\begin{array}{l}\text { Alcoholics } \\
n=45\end{array}$ & Non-alcoholics $n=295$ & $p$ value \\
\hline \multicolumn{4}{|l|}{ Patient characteristics before and on admission* } \\
\hline Age (years) & $53(44-59)$ & $58(39-70)$ & 0.124 \\
\hline Male $(\%)$ & $39 / 45(86.7)$ & $172 / 295(58.3)$ & $<0.001$ \\
\hline Headache $(\%)$ & $10 / 43(23.3)$ & $146 / 279(52.3)$ & $<0.001$ \\
\hline Fever $\geq 37.8{ }^{\circ} \mathrm{C}(\%)$ & $31 / 45(68.9)$ & $235 / 285(82.4)$ & 0.052 \\
\hline Glasgow Coma Scale score & $10(7-12)$ & $12(9-14)$ & $<0.001$ \\
\hline Neck stiffness $(\%)$ & $38 / 45(84.4)$ & $221 / 283(78.1)$ & 0.597 \\
\hline Nausea/vomiting (\%) & $5 / 44(11.4)$ & $97 / 289(33.6)$ & 0.005 \\
\hline Seizures $(\%)$ & $15 / 45(33.3)$ & $37 / 294(12.6)$ & $<0.001$ \\
\hline Ataxia $(\%)$ & $2 / 43(4.4)$ & $13 / 289(4.5)$ & 0.987 \\
\hline Aphasia (\%) & $4 / 41(8.9)$ & $25 / 286(8.7)$ & 0.974 \\
\hline Cranial nerve paralysis $(\%)$ & $2 / 45(4.4)$ & $20 / 293(6.8)$ & 0.547 \\
\hline Hemiparesis (\%) & $9 / 45(20)$ & $31 / 293(10.6)$ & 0.069 \\
\hline Vertebral pain/back pain (\%) & $5 / 44(11.4)$ & 29/281 (10.3) & 0.834 \\
\hline Skin rash $(\%)$ & $2 / 45(4.4)$ & $21 / 285(7.4)$ & 0.474 \\
\hline \multicolumn{4}{|l|}{ Disease severity/outcome } \\
\hline SOFA score on admission & $3(2-6)$ & $2(1-5)$ & 0.002 \\
\hline Requiring ICU admission (\%) & $22 / 45(48.9)$ & $111 / 295(37.6)$ & 0.154 \\
\hline Glasgow Outcome Score & $3(1-5)$ & $5(3-5)$ & $<0.001$ \\
\hline Mortality (\%) & $11 / 45(24.4)$ & $45 / 292(15.4)$ & 0.130 \\
\hline \multicolumn{4}{|l|}{ Identified pathogen (\%) } \\
\hline Streptococcus pneumoniae & $8 / 45(17.8)$ & $58 / 295(19.7)$ & 0.766 \\
\hline Staphylococcus & $4 / 45(8.9)$ & $37 / 295(12.5)$ & 0.483 \\
\hline Neisseria meningitidis & $5 / 45(11.1)$ & $25 / 295(8.5)$ & 0.561 \\
\hline Listeria monocytogenes & $0 / 45(0)$ & $24 / 295(8.14)$ & 0.094 \\
\hline Mycobacterium tuberculosis & $3 / 45(6.7)$ & $17 / 295(5.8)$ & 0.810 \\
\hline Other Gram-positive & $6 / 45(13.3)$ & $17 / 295(5.8)$ & 0.060 \\
\hline Other Gram-negative & $1 / 45(2.2)$ & $11 / 295(3.7)$ & 0.610 \\
\hline Haemophilus influenzae & $0 / 45(0)$ & $4 / 295(1.4)$ & 0.432 \\
\hline Unknown & $18 / 45(40)$ & $102 / 295(34.6)$ & 0.478 \\
\hline Diagnostic LP after antibiotic treatment initiation & $26 / 39(66.7)$ & $134 / 245(54.7)$ & 0.161 \\
\hline
\end{tabular}

*Data are presented as median (interquartile range) or $n / N(\%), p$ values $<0.05$ are italicized

$L P$ lumbar puncture, SOFA Sequential Organ Failure Assessment score, ICU intensive care unit 
Table 2 Laboratory blood and cerebrospinal fluid (CSF) results in alcoholic and non-alcoholic patients with bacterial meningitis

\begin{tabular}{llll}
\hline & Alcoholics & Non-alcoholics & $p$ value \\
\hline Blood test results* & & & \\
CRP $(\mathrm{mg} / \mathrm{L})$ & $208.5(76.5-327)$ & $218.5(68-328)$ & 0.750 \\
Lactic acid $(\mathrm{mmol} / \mathrm{L})$ & $1.91(1.45-2.86)$ & $2.00(1.58-2.93)$ & 0.822 \\
WBC $(1000 \mathrm{cells} / \mu \mathrm{L})$ & $14.5(10.1-19.1)$ & $14.3(10.1-20.0)$ & 0.827 \\
PLT $(1000 \mathrm{cells} / \mu \mathrm{L})$ & $188(91-287)$ & $189(138-247)$ & 0.986 \\
PCT $(\mathrm{ng} / \mathrm{mL})$ & $3.20(0.46-8.88)$ & $3.33(0.39-13.2)$ & 0.958 \\
D-dimers $(\mu \mathrm{g} / \mathrm{L})$ & $3273(1751-5817)$ & $2241(1159-4262)$ & 0.013 \\
Creatinine $(\mu \mathrm{mol} / \mathrm{L})$ & $63(55-91)$ & $68(55-85)$ & 0.533 \\
Urea $(\mathrm{mmol} / \mathrm{L})$ & $6.02(4.47-9.72)$ & $6.14(4.40-10.29)$ & 0.840 \\
CSF test results & & & \\
Cytosis $(\mathrm{cells} / \mu \mathrm{L})$ & $539(259-4480)$ & $1110(243-3880)$ & 0.846 \\
Granulocytes $(\%)$ & $88.5(54-95)$ & $87.5(70-95)$ & 0.838 \\
Protein $(\mathrm{g} / \mathrm{L})$ & $3.67(1.81-7.28)$ & $2.83(1.33-6.36)$ & 0.178 \\
Glucose $(\mathrm{mmol} / \mathrm{L})$ & $0.58(0-2.3)$ & $1.97(0.11-3.40)$ & 0.025 \\
Lactic acid $(\mathrm{mmol} / \mathrm{L})$ & $7.2(5.6-12.2)$ & $5.5(3.0-10.7)$ & 0.118 \\
Chlorides $(\mathrm{mmol} / \mathrm{L})$ & $112(109-122)$ & $117(113-121)$ & 0.101 \\
\hline
\end{tabular}

*Data are presented as median (interquartile range), $p$ values $<0.05$ are italicized

$C R P$ C-reactive protein, $W B C$ white blood cells, $P L T$ platelets, $P C T$ procalcitonin, $C S F$ cerebrospinal fluid alcohol abuse were a standard part of medical interview, and information was obtained from patients and/or their relatives.

The Mann-Whitney $U$ test was used to compare continuous variables, and the chi-square test was used to evaluate nominal variables. Logistic regression was used to calculate adjusted odds ratios and to determine variables independently associated with alcoholism and those independently influencing outcome reflected by GOS. Since GOS is not a nominal but continuous variable, we used the general linear model to calculate the coefficients for this analysis. Statistical analyses were performed using program $\mathrm{R}$ version 3.5.2 [15].

Table 3 Multiple logistic regression analysis of factors independently associated with alcoholism in patients with bacterial meningitis

\begin{tabular}{llll}
\hline Variable* & $p$ value & OR & $95 \%$ CI \\
\hline GCS & 0.036 & 0.716 & $0.523-0.980$ \\
GOS & 0.780 & 0.933 & $0.575-1.515$ \\
SOFA & 0.075 & 0.814 & $0.649-1.021$ \\
CSF glucose & 0.335 & 0.850 & $0.611-1.183$ \\
Male gender & 0.042 & 4.617 & $1.060-20.113$ \\
Headache & 0.316 & 0.535 & $0.157-1.819$ \\
Nausea/vomiting & 0.040 & 0.205 & $0.045-0.930$ \\
Seizures & 0.041 & 4.580 & $1.065-19.706$ \\
\hline
\end{tabular}

* Results are presented as odds ratio (OR) and confidence interval (CI), $p$ values $<0.05$ are italicized

GCS Glasgow Coma Scale, GOS Glasgow Outcome Scale, SOFA Sepsisrelated Organ Failure Assessment score, CSF glucose concentration of glucose in cerebrospinal fluid

\section{Results}

The final analysis included 340 patients with bacterial meningitis (211 men and 129 women, median age 57, interquartile range [IQR] 41-69). Among this group, 45 (13.2\%) patients were considered alcoholics (39 men and 6 women, median age 53, IQR 44-59).

At admission, alcoholic patients were more likely to present with seizures $(33.3 \%$ vs $12.6 \%, p<0.001)$ (Table 1$)$ but were less likely to complain of headache $(23.3 \%$ vs $52.3 \%$, $p<0.001)$ and nausea/vomiting $(11.4 \%$ vs $33.6 \%, p=0.005)$. Furthermore, they scored higher on the SOFA (median 3 [IQR 2-6] vs median 2 [IQR 1-5], $p=0.002$ ) and lower on the GCS (median 10 [IQR 7-12] vs median 12 [IQR 9-14], $p<0.001$ ). Alcoholic patients were also more likely to require intensive care unit (ICU) admission (48.9\% vs $37.6 \%$ ), and their mortality was higher (24.4\% vs $15.4 \%$ ), but these differences did not reach statistical significance. The clinical outcome reflected by the GOS was significantly worse among alcoholics (median 3 [IQR 1-5] vs median 5 [IQR 3-5], $p<0.001$; Table 1).

Analysis of laboratory parameters (Table 2) revealed that alcoholic patients had significantly higher serum concentration of D-dimers (median $3273 \mu \mathrm{g} / \mathrm{L}$ [IQR 1751-5817] vs median $2241 \mu \mathrm{g} / \mathrm{L}$ [IQR 1159-4262], $p=0.013$ ) and lower concentration of glucose in CSF (median $0.58 \mathrm{mmol} / \mathrm{L}$ [IQR $0-2.3$ ] vs median 1.97 [IQR 0.11-3.40], $p=0.025$; Table 2).

In multiple logistic regression analysis (Table 3 ), alcoholism was independently associated with a lower GCS score (OR 0.716, 95\% CI 0.523-0.980, $p=0.036$ ), male gender 
(OR 4.617, 95\% CI 1.060-20.113, $p=0.042$ ), the presence of seizures (OR 4.580, 95\% CI 1.065-19.706, $p=0.041$ ), and the absence of nausea/vomiting (OR 0.205 , 95\% CI $0.045-$ $0.930, p=0.040$ ). Furthermore, alcoholism, lower GCS score, and higher urea blood concentration were independently associated with worse prognosis as assessed by GOS (Table 4).

An etiological factor was identified only in $60 \%$ of alcoholics and $65 \%$ of non-alcoholics (Table 1). However, in $67 \%$ of alcoholics and in $55 \%$ of non-alcoholics, antibiotic treatment initiation preceded diagnostic spinal tap.

\section{Discussion}

According to national survey data [16], alcoholics constitute approximately $2 \%$ of the Polish general adult population, but among our patients with $\mathrm{BM}$, this proportion was $13 \%$ which might be a direct consequence of impaired immune response to bacterial pathogens related to chronic alcohol abuse [17-20]. In the nationwide cohort study conducted in the Netherlands, the proportion of alcoholics in BM patients was also higher than in general population $[7,11]$.

Compared with non-alcoholics, alcohol abusers were less likely to present with fever, headache, and nausea. The absence of such typical symptoms of BM [21] might cause diagnostic problems and in effect result in the delay of treatment initiation. Another difference in the clinical presentation was higher incidence of seizures among alcoholic patients (33\% vs $13 \%, p<0.001)$. While high incidence of seizures among alcohol abusers presenting with BM is a well-known phenomenon, the numbers in previous reports were lower and ranged from 13 to $18 \%$ [11, 12]. Furthermore, in our multivariate analysis, the presence of seizures was independently associated with alcoholism but not with outcome.

The presence of seizures and other signs and symptoms associated with the alcohol withdrawal syndrome or even alcohol intoxication itself could also negatively affect consciousness level: in our study, alcoholic patients scored significantly lower on the GCS scale at admission compared with non-alcoholics. These findings are compatible with previous studies of van Veen et al. [11] and Weisfelt et al. [12].

While alcohol abuse was not an independent predictor for mortality in multivariate analysis, it was associated with worse outcome as measured by the GOS. These results are similar to those reported by Wiesfelt et al. [22] who also found that alcoholism is associated with unfavorable outcome but not with higher mortality.

In addition to alcohol, low GCS score and high blood urea levels were independently associated with worse outcome (Table 4). The influence of GCS on outcome is not surprising and was previously reported by others [23, 24], while increased urea might identify a subset of patients with multiple organ failure. With the exception of blood D-dimer levels and CSF glucose levels, no differences were found in the results of routine tests between alcoholic and non-alcoholic patients. High blood D-dimer levels are common in chronic alcohol abusers and could be the effect of hemostatic system activation related to oxidative stress [25]. Interestingly, low concentration of glucose in the CSF was previously correlated with adverse clinical outcomes in patients with BM [26].

Streptococcus pneumoniae was the most common causative microorganism (19.4\%) in our patients (Table 1), but its
Table 4 Multiple logistic regression analysis of factors independently associated with lower Glasgow Outcome Score (GOS) in patients with bacterial meningitis

\begin{tabular}{llll}
\hline Variable & Regression coefficient & $95 \%$ CI & $p$ value \\
\hline Alcoholism & -0.636 & $-1.209-0.063$ & 0.031 \\
Seizures & 0.180 & $-0.037-0.728$ & 0.521 \\
Etiology unknown & 0.100 & $-0.353-0.552$ & 0.667 \\
Streptococcus pneumoniae & -0.010 & $-0.669-0.470$ & 0.732 \\
Neisseria meningitidis & 0.512 & $-0.244-1.267$ & 0.186 \\
Age & -0.009 & $-0.021-0.003$ & 0.161 \\
GCS & 0.144 & $0.061-0.226$ & 0.001 \\
SOFA & -0.068 & $-0.160-0.025$ & 0.154 \\
CRP & 0.001 & $-0.001-0.002$ & 0.841 \\
PLT & 0.001 & $-0.001-0.002$ & 0.633 \\
PCT & -0.001 & $-0.008-0.005$ & 0.665 \\
Urea & -0.052 & $-0.095-0.009$ & 0.018 \\
CSF protein & -0.007 & $-0.040-0.025$ & 0.656 \\
CSF glucose & 0.034 & $-0.061-0.129$ & 0.484 \\
\hline
\end{tabular}

CI confidence interval, GCS Glasgow Coma Scale, SOFA Sepsis-related Organ Failure Assessment score, PLT platelet level, $P C T$ concentration of procalcitonin in blood, CSF protein concentration of protein in cerebrospinal fluid, CSF glucose concentration of glucose in cerebrospinal fluid, $p$ values $<0.05$ are italicized 
prevalence was not as high as in some other European studies [27-29]. Such relatively low prevalence of Streptococcus pneumoniae is not a local phenomenon confined to our center, as it accounted for only $22 \%$ of BM cases registered in Poland [2].

In conclusion, we found that alcoholic patients with $\mathrm{BM}$, when compared with their non-alcoholic counterparts, are more likely to present with seizures and more severely altered mental status and have an increased risk for unfavorable outcome.

Funding Marcin Paciorek was supported by The Research Development Foundation of the Hospital for Infectious Diseases (FRN 004/2019).

Magdalena Zielenkiewicz was supported by The Research Development Foundation of the Hospital for Infectious Diseases (FRN 004/2019)

Tomasz Laskus was supported by The National Science Center (2017/25/B/NZ6/01463).

Compliance with ethical standards Funding institutions did not play any role in the study design, data collection, and analysis, decision to publish, or preparation of the manuscript.

Ethical approval This study was approved by the Warsaw Medical University Ethics Committee (approval number 3452M4/2019). Since all data were analyzed anonymously and retrospectively informed consent was not obtained.

Open Access This article is distributed under the terms of the Creative Commons Attribution 4.0 International License (http:// creativecommons.org/licenses/by/4.0/), which permits unrestricted use, distribution, and reproduction in any medium, provided you give appropriate credit to the original author(s) and the source, provide a link to the Creative Commons license, and indicate if changes were made.

\section{References}

1. Paradowska-Stankiewicz I, Piotrowska A (2016) Meningitis and encephalitis in Poland in 2014. Przegl Epidemiol 70(3):349-357

2. Paradowska-Stankiewicz I, Piotrowska A (2017) Meningitis and encephalitis in Poland in 2015. Przegl Epidemiol 71(4):493-500

3. http://wwwold.pzh.gov.pl/oldpage/epimeld/2017/Ch_2017_ wstepne dane.pdf

4. Polkowska A, Toropainen M, Ollgren J, Lyytikainen O, Nuorti JP (2017) Bacterial meningitis in Finland, 1995-2014: a populationbased observational study. BMJ Open 7(5):e015080. https://doi. org/10.1136/bmjopen-2016-015080

5. Bijlsma MW, Brouwer MC, Kasanmoentalib ES, Kloek AT, Lucas MJ, Tanck MW, van der Ende A, van de Beek D (2016) Community-acquired bacterial meningitis in adults in the Netherlands, 2006-14: a prospective cohort study. Lancet Infect Dis 16(3):339-347. https://doi.org/10.1016/s1473-3099(15) 00430-2

6. Okike IO, Ribeiro S, Ramsay ME, Heath PT, Sharland M, Ladhani SN (2014) Trends in bacterial, mycobacterial, and fungal meningitis in England and Wales 2004-11: an observational study. Lancet Infect Dis 14(4):301-307. https://doi.org/10.1016/s1473-3099(13) 70332-3
7. https://apps.who.int/iris/bitstream/handle/10665/274603/ 9789241565639-eng.pdf

8. Samokhvalov AV, Irving HM, Rehm J (2010) Alcohol consumption as a risk factor for pneumonia: a systematic review and meta-analysis. Epidemiol Infect 138(12):1789-1795. https://doi.org/10.1017/ s0950268810000774

9. Brown LA, Harris FL, Ping XD, Gauthier TW (2004) Chronic ethanol ingestion and the risk of acute lung injury: a role for glutathione availability? Alcohol (Fayetteville, NY) 33(3):191-197. https://doi.org/10.1016/j.alcohol.2004.08.002

10. Sachs CW, Christensen RH, Pratt PC, Lynn WS (1990) Neutrophil elastase activity and superoxide production are diminished in neutrophils of alcoholics. Am Rev Respir Dis 141(5 Pt 1):1249-1255. https://doi.org/10.1164/ajrccm/141.5 Pt 1.1249

11. van Veen KE, Brouwer MC, van der Ende A, van de Beek D (2017) Bacterial meningitis in alcoholic patients: a population-based prospective study. J Infect 74(4):352-357. https://doi.org/10.1016/j. jinf.2017.01.001

12. Weisfelt M, de Gans J, van der Ende A, van de Beek D (2010) Community-acquired bacterial meningitis in alcoholic patients. PLoS One 5(2):e9102. https://doi.org/10.1371/journal.pone. 0009102

13. koroun.edu.pl/wp-content/uploads/2017/10/Rekomendacje-uk1nerwowy_2011.pdf

14. http://www.who.int/substance abuse/terminology/who lexicon/ en/

15. https://www.r-project.org

16. http://www.parpa.pl/index.php/33-analizy-badania-raporty/132statystyki

17. Bhatty M, Pruett SB, Swiatlo E, Nanduri B (2011) Alcohol abuse and Streptococcus pneumoniae infections: consideration of virulence factors and impaired immune responses. Alcohol (Fayetteville, NY) 45(6):523-539. https://doi.org/10.1016/j. alcohol.2011.02.305

18. Jerrells TR, Slukvin I, Sibley D, Fuseler J (1994) Increased susceptibility of experimental animals to infectious organisms as a consequence of ethanol consumption. Alcohol Alcohol (Oxford, Oxfordshire) Supplement 2:425-430

19. Gandhi JA, Ekhar VV, Asplund MB, Abdulkareem AF, Ahmadi M, Coelho C, Martinez LR (2014) Alcohol enhances Acinetobacter baumannii-associated pneumonia and systemic dissemination by impairing neutrophil antimicrobial activity in a murine model of infection. PLoS One 9(4):e95707. https://doi.org/10.1371/journal. pone.0095707

20. Karavitis J, Kovacs EJ (2011) Macrophage phagocytosis: effects of environmental pollutants, alcohol, cigarette smoke, and other external factors. J Leukoc Biol 90(6):1065-1078. https://doi.org/10. $1189 / \mathrm{jlb} .0311114$

21. van de Beek D, de Gans J, Spanjaard L, Weisfelt M, Reitsma JB, Vermeulen M (2004) Clinical features and prognostic factors in adults with bacterial meningitis. N Engl J Med 351(18):18491859. https://doi.org/10.1056/NEJMoa040845

22. Taylor AN, Tio DL, Heng NS, Yirmiya R (2002) Alcohol consumption attenuates febrile responses to lipopolysaccharide and interleukin-1 beta in male rats. Alcohol Clin Exp Res 26(1):44-52

23. Jordan I, Calzada Y, Monfort L, Vila-Perez D, Felipe A, Ortiz J, Cambra FJ, Munoz-Almagro C (2016) Clinical, biochemical and microbiological factors associated with the prognosis of pneumococcal meningitis in children. Enferm Infecc Microbiol Clin 34(2): 101-107. https://doi.org/10.1016/j.eimc.2015.03.004

24. Pietraszek-Grzywaczewska I, Bernas S, Lojko P, Piechota A, Piechota M (2016) Predictive value of the APACHE II, SAPS II, SOFA and GCS scoring systems in patients with severe purulent bacterial meningitis. Anaesthesiol Intensive Ther 48(3):175-179. https://doi.org/10.5603/AIT.a2016.0030 
25. Trotti R, Carratelli M, Barbieri M, Micieli G, Bosone D, Rondanelli M, Bo P (2001) Oxidative stress and a thrombophilic condition in alcoholics without severe liver disease. Haematologica 86(1):85-91

26. Shrikanth V, Salazar L, Khoury N, Wootton S, Hasbun R (2015) Hypoglycorrhachia in adults with community-acquired meningitis: etiologies and prognostic significance. Int J Infect Dis : IJID : official publication of the International Society for Infectious Diseases 39:39-43. https://doi.org/10.1016/j.ijid.2015.08.001

27. NR Netherlands Reference Laboratory for Bacterial Meningitis (AMC/ RIVM) (2011) Bacterial meningitis in the Netherlands annual report 2010. University of Amsterdam, Amsterdam

28. Bodilsen J, Dalager-Pedersen M, Schonheyder HC, Nielsen H (2014) Dexamethasone treatment and prognostic factors in community-acquired bacterial meningitis: a Danish retrospective population-based cohort study. Scand J Infect Dis 46(6):418-425. https://doi.org/10.3109/00365548.2014.887223

29. Gjini AB, Stuart JM, Lawlor DA, Cartwright KA, Christensen H, Ramsay M, Heyderman RS (2006) Changing epidemiology of bacterial meningitis among adults in England and Wales 1991-2002. Epidemiol Infect 134(3):567-569. https://doi.org/10.1017/ s0950268805005595

Publisher's note Springer Nature remains neutral with regard to jurisdictional claims in published maps and institutional affiliations. 